\title{
Localization and Characterization of Melatonin Receptors in Rodent Brain by in vitro Autoradiography
}

\author{
David R. Weaver, Scott A. Rivkees, and Steven M. Reppert \\ Laboratory of Developmental Chronobiology, Children's Service, Massachusetts General Hospital, and Department of \\ Pediatrics and Program in Neuroscience, Harvard Medical School, Boston, Massachusetts 02114
}

\begin{abstract}
Little is known of the neural sites of action for the pineal hormone, melatonin. Thus, we developed an in vitro autoradiographic method using ${ }^{125}$-labeled melatonin (I-MEL) to study putative melatonin receptors in rodent brain. We first determined optimal in vitro labeling conditions for autoradiographic detection of I-MEL binding sites in rat median eminence, the most intensely labeled area in the rat brain. We then assessed the pharmacologic and kinetic properties of I-MEL binding sites in rat median eminence by quantitative autoradiography. These sites have high affinity for I-MEL (equilibrium dissociation constant $=43 \mathrm{pM}$ ). I-MEL binding was inhibited by nanomolar concentrations of melatonin or 6-chloromelatonin, but was not inhibited by serotonin, dopamine, or norepinephrine $(100 \mu \mathrm{M})$. These results suggest that I-MEL binding sites identified by in vitro autoradiography represent specific, high-affinity melatonin receptors. Studies of the distribution of I-MEL binding in rat, Syrian hamster, and Djungarian hamster brain confirm that the median eminence and suprachiasmatic nucleus are major sites of I-MEL. binding in rodent brain; other brain areas labeled in one or more of these species were the thalamus (paraventricular, anteroventral, and reuniens nuclei, nucleus of the stria medullaris, and medial part of the lateral habenular nucleus), hypothalamus (dorsomedial nucleus), subiculum, and area postrema. The presence of putative melatonin receptors in the suprachiasmatic nuclei and median eminence of these rodent species suggests that these brain regions are important loci for melatonin effects on circadian rhythms and reproduction.
\end{abstract}

The hormone melatonin ( $\mathrm{N}$-acetyl-5-methoxytryptamine) is produced rhythmically by the vertebrate pineal gland, with elevated levels occurring at night. The most well-documented role of melatonin in mammals is the regulation of photoperiodic responses, especially reproduction (for reviews, see Karsch et al., 1984; Turek et al., 1984; Tamarkin et al., 1985; Underwood and Goldman, 1987). The hypothalamus appears to be the prime site of melatonin action in the modulation of reproduction,

\footnotetext{
Received Oct. 21, 1988; revised Dec. 12, 1988; accepted Dec. 16, 1988.

We thank Ignacio Provencio for expert technical assistance and Dr. Greg Crosby for use of his image-analysis system. This work was supported by NRSA HD06976 (D.R.W.), the Pediatric Career Scientist Training Program Award under PHS Grant U10-HD-00850 (S.A.R.), and HD-14427 (S.M.R.). S.M.R. is an Established Investigator of the American Heart Association. Portions of this work have been previously reported (Weaver et al., 1988a, b).

Correspondence should be addressed to David R. Weaver, Ph.D., at the above address.

Copyright (C) 1989 Society for Neuroscience $0270-6474 / 89 / 072581-10 \$ 02.00 / 0$
}

based on brain lesion studies (Bittman et al., 1979; Rusak, 1980) and experiments using intracerebral melatonin implants (Glass and Lynch, 1981).

Another effect of melatonin is its ability to influence circadian rhythmicity (see Underwood and Goldman, 1987, for review). In mammals, pinealectomy or melatonin implants do not affect the period of free-running circadian rhythms (Cheung and McCormack, 1982) and pinealectomy has only minor effects on the rate of reentrainment following phase shifts of the lighting cycle. However, daily melatonin administration can entrain rats (Redman et al., 1983). The suprachiasmatic nuclei (SCN) function as a biological clock in rodents and nonhuman primates, regulating a variety of circadian rhythms (Moore, 1983). The entraining effect of melatonin may be due to an effect on the $\mathrm{SCN}$, as SCN lesions prevent the entraining effect of melatonin (Cassone et al., 1986).

With the recent discovery that the indole nucleus of melatonin can be directly iodinated (Vakkuri et al., 1984), a radioligand ('25I-labeled mclatonin; I-MEL) of high specific activity (ca. 2000 $\mathrm{Ci} / \mathrm{mmol}$ ) is now available for investigating melatonin sites of action. The biological activity of iodinated melatonin, both in vivo (Weaver et al., 1988c) and in vitro (Dubocovich and Takahashi, 1987), strongly suggests that this molecule interacts at biologically relevant sites; localization and characterization of these sites is a critical step in understanding the mechanism of melatonin action.

In vitro autoradiographic techniques using I-MEL have recently been developed to localize putative melatonin receptors within individual brain nuclei (Vaněček et al., 1987; Reppert et al., 1988; Weaver et al., 1988c). In the present study, we characterized the I-MEL binding site in rat median eminence by quantitative receptor autoradiography. To define potential sites of melatonin action in species where melatonin effects on physiology have been most extensively studied, we also examined the distribution of I-MEL binding sites in brains of adult male rats and Syrian and Djungarian hamsters.

\section{Materials and Methods}

Preparation of I-MEL. Melatonin was iodinated by the method of Vakkuri et al. (1984) and purified by high-pressure liquid chromatography (HPLC). Briefly, $10 \mu \mathrm{g}$ melatonin ( $1 \mu \mathrm{g} / \mu \mathrm{l}$ in $100 \%$ ethanol; Sigma, St. Louis, $\mathrm{MO}$ ) and $\mathrm{Na}^{125} \mathrm{I}(2 \mathrm{mCi}$; specific activity, $1775-2113 \mathrm{Ci} / \mathrm{mmol}$; Amersham, Arlington Heights, IL) were combined in an Eppendorf tube coated with Iodogen $(10 \mu \mathrm{g}, 1,3,4,6$ tetrachloro-3a,6a-diphenyl-glycoluril; Pierce Chemical Co., Rockford, IL). The reaction was terminated after $60 \mathrm{sec}$ by addition of $200 \mu \mathrm{l}$ chloroform. The organic phase was evaporated to dryness under nitrogen and resuspended in $100 \%$ ethanol. The reaction product was then injected onto an HPLC column (UItrasphere $5 \mu \mathrm{m}, 4.6 \mathrm{~mm} \times 15 \mathrm{~cm}$; Beckman, San Ramon, CA) and 
eluted with a linear gradient of isopropanol (10-40\% over $30 \mathrm{~min}$ at $\mathrm{ml} / \mathrm{min}$ ) in distilled water. Fractions were collected every $30 \mathrm{sec}$. Frac tions (4) eluting at ca. 30\% isopropanol (retention time, $20 \mathrm{~min}$ ) contained a peak of radioactivity composed primarily of I-MEL. Under these conditions, tritiated melatonin (2-aminoethyl- ${ }^{3} \mathrm{H}, 43.9 \mathrm{Ci} / \mathrm{mmol}$ New England Nuclear, Boston, MA) eluted at $20 \%$ isopropanol (retention time, ca. $10 \mathrm{~min}$ ) and was clearly separated from I-MEL. Each fraction was extracted with $5 \mathrm{vol}$ of chloroform, and the chloroform was washed with $1 \mathrm{vol} 0.45 \mathrm{M}$ sodium borate buffer ( $\mathrm{pH}$ 9.7). The organic fractions were combined and dried under nitrogen. I-MEL was dissolved in $100 \%$ ethanol and diluted in buffer. Iodination yield (counts I-MEL recovered/counts $\mathrm{Na}^{125}$ I initially) was approximately $10 \%$.

Thin-layer chromatography [0.25 mm silica gel (F-254), EM reagents division, Brinkman Instruments, Inc., Westbury, NY] using ethyl acetate as the mobile phase (Weaver et al., 1988c) was used to test purity of I-MEL prior to autoradiographic labeling experiments. The radioactivity migrated as a single peak that comigrated with nonradioactive iodomelatonin standard. I-MEL was $>95 \%$ pure and remained stable for at least 2 months after preparation.

Animals. Male Sprague-Dawley rats (28-35 d old) were obtained from Charles River Breeding Laboratories (Kingston, NY) and Zivic-Miller Laboratories (Allison Park, PA); no differences in distribution or intensity of I-MEL binding were noted between animals from the 2 suppliers. Male Syrian (golden) hamsters (Mesocricetus auratus, LAK:LVG SYR, 48-54 d old) were obtained from Charles River Breeding Laboratories (Wilmington, MA), and 60-d-old male Djungarian (Siberian) hamsters (Phodopus sungorus) were from our colony, established in 1985 with animals provided by Drs. D. A. Damassa, M. H. Stetson, and G. N. Wade. Rats were housed in a light-dark cycle of $12 \mathrm{hr}$ light: $12 \mathrm{hr}$ dark (12L:12D), Syrian hamsters were housed in 14L:10D, and Djungarian hamsters were housed in 16L:8D.

Preparation of tissue for autoradiography. Animals were killed by decapitation in the afternoon, 3-6 hr before lights off. Brains were removed, frozen in cooled $\left(-20^{\circ} \mathrm{C}\right) 2$-methylbutane, and stored at $-70^{\circ} \mathrm{C}$ until sectioning. Coronal $20 \mu \mathrm{m}$ sections were cut in a cryostat $\left(-20^{\circ} \mathrm{C}\right)$ and thaw-mounted onto chrome alum gel-coated slides. Sections were air-dried for $10-15 \mathrm{~min}$, refrozen, and stored at $-70^{\circ} \mathrm{C}$.

For atlases, sections were distributed to slides such that each slide contained 2 or 3 consecutive sections every $240 \mu \mathrm{m}$ (i.e., sections were collected as a 2 -in-12 or 3-in-12 series). For optimization and characterization studies, sections on a single slide were at $480-560 \mu \mathrm{m}$ intervals (collected as a 3 -in-24, 2 -in-24, or 2 -in-28 series). Image analysis was performed on sections at several intervals on each slide to compensate for variation in anatomy.

In vitro autoradiographic labeling. Slide-mounted tissue sections were warmed to room temperature and placed sequentially into preincubation buffer, incubation buffer, and wash buffers. For optimization and pharmacology experiments, a slide from each animal was preincubated in buffer $(0.02 \mathrm{M}$ sodium phosphate buffered $0.15 \mathrm{M}$ saline, $\mathrm{pH} 7.4$, containing $0.1 \% \mathrm{BSA}$; PBS/BSA) for $1 \mathrm{hr}$ at $22^{\circ} \mathrm{C}$, incubated with I-MEL (100 pM in PBS/BSA, $1 \mathrm{hr}, 22^{\circ} \mathrm{C}$ ), and then washed (PBS/BSA, $15 \mathrm{~min}$ at $0^{\circ} \mathrm{C}$, followed by PBS, $15 \mathrm{~min}$ at $0^{\circ} \mathrm{C}$ ) as previously described (Reppert et al., 1988; Weaver et al., 1988c). Other slides from each animal were used to assess the effects of varying reaction conditions or the effects of drugs on I-MEL binding; data are expressed relative to slides run under the standard conditions (above). Atlases of the distribution of I-MEL binding sites were also performed using these standard conditions.

Generation of autoradiograms. After in vitro labeling, slides were blown dry with cool air, attached to cardboard backing, and placed in $X$-ray cassettes along with standards (see below). Autoradiograms were generated by apposition of LKB Ultrofilm (LKB Pharmacia, Westminster, MD) to slides for 6-10 d (for quantitative studies) or 3 weeks (for atlases). Films were processed using Kodak D-19 developer (4 min, $22^{\circ} \mathrm{C}$ ), indicator stop bath $(30 \mathrm{sec})$, and Kodak Rapid fixer with hardener 4 min. Sections were stained with cresyl violet or toluidine blue and examined by light microscopy to verify location of structures, with reference to the atlas of Paxinos and Watson (1985). When necessary, films were superimposed on the stained sections to define the anatomical boundaries of labeled areas.

Quantitative analysis of autoradiograms. Quantitative assessment of autoradiograms was pcrformed using the Drexel University Image Processing Center "Brain Software Package" run on an IBM AT computer (McEachron et al., 1987). Images were recorded with a Circon MV9015-H monochrome microvideo camera. Absolute optical density values were calibrated using a photographic step tablet (Kodak \#3, Rochester, NY). For quantitative assessment, optical density values of individual brain regions were converted to radioactivity by comparison with radioactive standards $\left(20-\mu\right.$ m-thick ${ }^{125} I$ microscales, batch \#4, Amersham) included on each film. A single set of ${ }^{125}$ I microscales was used for this series of experiments, and the amount of radioactivity in the standards was calculated to compensate for decay of the isotope for each set of films.

While the standard curve relating optical density and radioactivity could be described as linear for each film $(r \geq 0.90)$, linear plots poorly estimated the level of radioactivity at some optical density values (see Fig. 1). We therefore used a computer-generated best-fit multiparameter (cubic) equation (RRAIN program GU: BMFP), which provided a good fit throughout the optical density range examined (see Fig. 1).

Radioreceptor assay. Rat brains were removed rapidly, and brain regions were dissected with the aid of a dissecting microscope. For SCN and median eminence, 40 animals were used. Samples of cortex and hypothalamus (a dissection including both $\mathrm{SCN}$ and median eminence) were obtained from 8 other rats. Tissue was pooled by brain region, sonicated (Kontes microultrosonic cell disruptor, tune $=3$, power $=8$, $10 \mathrm{sec})$ in Tris buffer $\left(50 \mathrm{~mm}, \mathrm{pH} 7.4,4^{\circ} \mathrm{C}\right)$, and centrifuged $(50,000 \times$ $g, 20 \mathrm{~min}, 4^{\circ} \mathrm{C}$ ). Pellets (crude membrane preparation) were washed twice, resuspended in Tris buffer, frozen, and stored at $-70^{\circ} \mathrm{C}$ for up to 3 weeks before use.

For assay, aliquots of membrane preparation (100 $\mu \mathrm{g}$ protein) were incubated with I-MEL (50 pM) in a final volume of $200 \mu \mathrm{l}$ at $25^{\circ} \mathrm{C}$ for $30 \mathrm{~min}$. The incubation was terminated by filtration through prewetted Whatman GF/B filters, followed by a rapid rinse with $10 \mathrm{ml}$ ice-cold buffer. Counts bound to protein were assessed by counting the filters in a gamma counter. Nonspecific binding was determined by including melatonin $(1 \mu \mathrm{M})$ in some tubes. Protein content was determined by the method of Bradford (1976) using BSA as standard.

Drugs. Melatonin, serotonin, dopamine, and norepinephrine were obtained from Sigma. 6-Chloromelatonin was donated by Dr. J. A. Clemens, Eli Lilly (Indianapolis, IN). Other chemicals were of reagent grade.

Statistics. Binding data were analyzed by the EBDA/LIGAND computer program (McPherson, 1985) to generate Scatchard plots and competition curves. The concentration of melatonin required to inhibit $50 \%$ of I-MEL binding $\left(\mathrm{IC}_{50}\right.$ ) value was also calculated (McPherson, 1985).

\section{Results}

\section{Optimization of reaction conditions}

We examined the effect of systematically varying each step of our in vitro autoradiographic method to identify optimal labeling conditions. Quantitative autoradiography was used to determine the effect of incubation duration, incubation temperature, preincubation duration, and wash duration on the level of I-MEL binding in rat median eminence.

Incubation duration and temperature dramatically influenced total I-MEL binding (Fig. $2 A$ ). Binding occurred more rapidly at $22^{\circ} \mathrm{C}$ than at $0^{\circ} \mathrm{C}$. At $22^{\circ} \mathrm{C}$, binding reached a plateau after $30 \mathrm{~min}$ and was stable for $4 \mathrm{hr}$. For this study, only total binding was assessed; other data showed that total and specific binding were generally very close.

Wash duration also affected the level of binding (Fig. 2B). During the first $5 \mathrm{~min}$, a rapid decrease in both specific and nonspecific binding occurred. Subsequently, nonspecific binding was undetectable, and specific binding remained stable for $2 \mathrm{hr}$. The presence of 2 components to the dissociation curve suggests that there may be 2 I-MEL binding sites that differ in affinity. The level of binding observed with a preincubation duration of 15 min was similar to that observed with a 60 min preincubation (101.5\%, $n=3$, data not shown).

These results indicate that the reaction conditions we have used in the past (Reppert et al., 1988; Weaver et al., 1988c) produce optimal labeling of I-MEL binding sites. These reaction conditions $\left(1 \mathrm{hr}\right.$ preincubation at $22^{\circ} \mathrm{C}, 1 \mathrm{hr}$ incubation at $22^{\circ} \mathrm{C}$, 


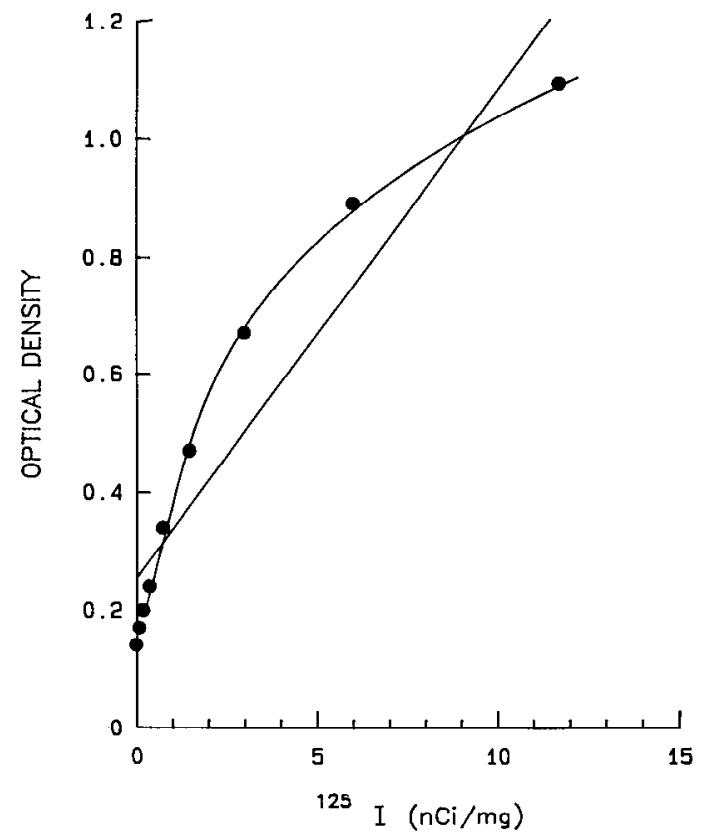

Figure 1. Relationship of optical density of LKB Ultrofilm to radioactivity ( ${ }^{123} \mathrm{I}$ microscales). Points represent the average of 4 films exposed for $6 \mathrm{~d}$ and processed together. SEs fall within the points. The line represents the best-fit regression line through the points $(y=0.082 x+$ $0.252 ; r=0.945$ ). The curve represents the computer-generated best-fit cubic equation for the same points $\left(y=-1.22+10.18 x-18.24 x^{2}+\right.$ $\left.18.25 x^{3}\right)$.

$2 \times 15 \mathrm{~min}$ washes at $0^{\circ} \mathrm{C}$ ) were therefore chosen for subsequent experiments.

\section{Autoradiographic characterization of I-MEL binding sites in rat median eminence}

Saturation studies. To determine the equilibrium dissociation constant $\left(K_{d}\right)$ for I-MEL binding sites, the I-MEL concentration in the incubation vessel was varied from 12.5 to $400 \mathrm{pM}$. Specific binding increased with I-MEL concentration from 12.5 to 200 pM and reached a plateau at 200 pM (Fig. 3), indicating that binding is saturable. Scatchard analysis of these results (Fig. 3, inset) indicated a single class of high-affinity binding sites $\left(K_{d}\right.$ $=43 \mathrm{pM}$, Hill coefficient $=0.98$ ). It is not possible to exclude the existence of a low-affinity site, however, as the range of I-MEL concentrations was not extended beyond 400 pM. Furthermore, a wash duration of 30 min may result in preferential examination of higher-affinity sites (see Fig. $2 B$ ).

Pharmacology. For pharmacologic characterization of I-MEL binding sites, melatonin, 6-chloromelatonin, \pm norepinephrine, serotonin, and dopamine were examined (Fig. 4). Melatonin potently inhibited I-MEL binding in rat median eminence (calculated $\mathrm{IC}_{50}$ for melatonin approximately $2 \mathrm{nM}$ ). Melatonin inhibited I-MEL binding in rat SCN and Djungarian hamster median eminence in a similar pattern (data not shown). 6-Chloromelatonin also potently displaced I-MEL binding in rat median eminence. Serotonin, norepinephrine, and dopamine did not significantly inhibit binding even at $100 \mu \mathrm{M}$.

Other characteristics. The I-MEL binding site is labile; specific binding was completely eliminated by boiling slide-mounted tissue sections $\left(20 \mathrm{~min}, 95^{\circ} \mathrm{C}\right)$ and by perfusion fixation with $10 \%$ neutral-buffered formalin. We have previously verified that
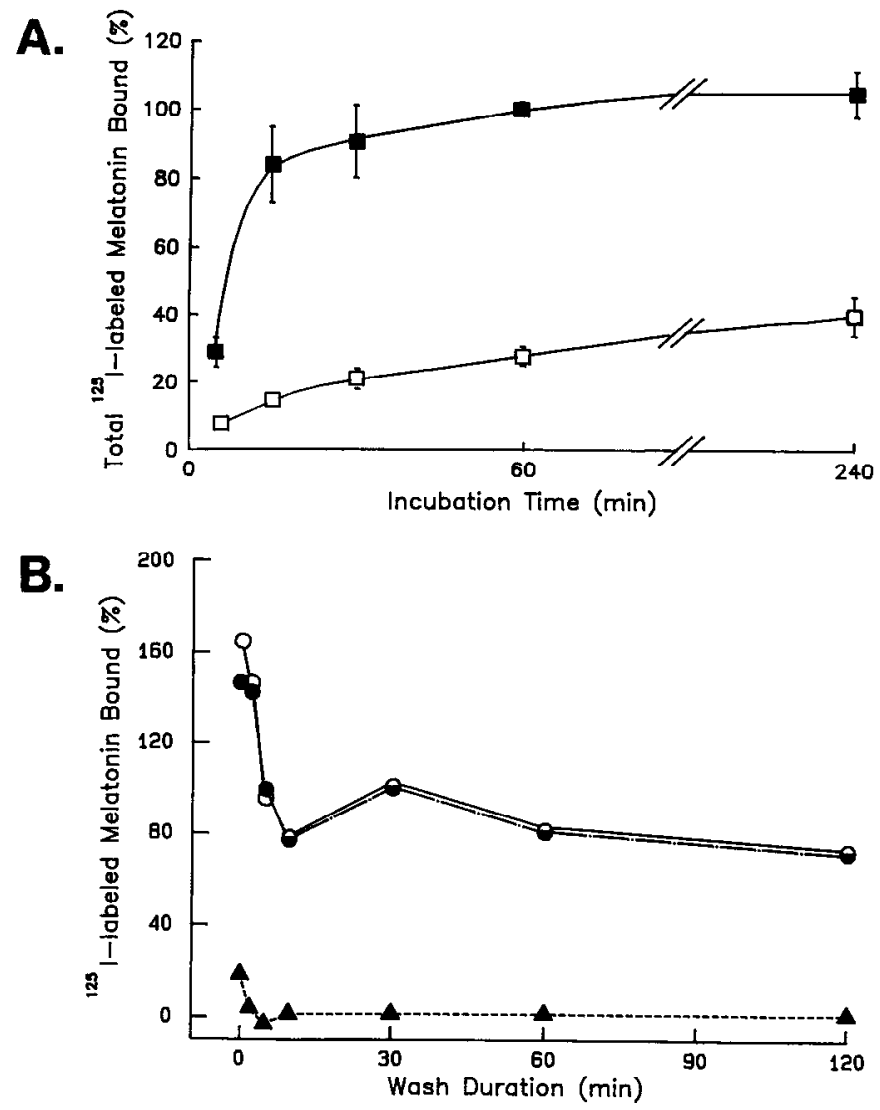

Figure 2. Optimization of in vitro autoradiographic conditions. $A$, Effect of incubation time and temperature $\left(22^{\circ} \mathrm{C}\right.$, solid rectangle; $0^{\circ} \mathrm{C}$, open rectangle) on total I-MEL binding. Data are from 6 animals at each point, expressed relative to standard conditions (incubation duration, $1 \mathrm{hr}$; incubation temperature, $22^{\circ} \mathrm{C}$ ), where $100 \%=3.76 \pm 0.43$ $\mathrm{nCi} / \mathrm{mg}$ (mean $\pm \mathrm{SE}$ ). $B$, Effect of wash duration on I-MEL binding. Specific binding (closed circles) is the difference between total binding (open circles) and nonspecific binding (triangles, determined in the presence of $1 \mu \mathrm{M}$ melatonin). Data are from 4 animals at each point, expressed relative to standard conditions $(2 \times 15 \mathrm{~min}$ washes; $100 \%-$ $4.89 \pm 0.60 \mathrm{nCi} / \mathrm{mg})$.

the radioactivity bound to tissue is I-MEL by thin-layer chromatography (Reppert et al., 1988).

\section{Distribution of I-MEL binding sites}

Rats. Specific labeling was observed in the hypothalamus (median eminence and $\mathrm{SCN}$ ), thalamus (anteroventral and paraventricular nuclei), subiculum, and area postrema (Fig. 5, Table 1). The external region of the median eminence was the most intensely labeled site in the rat brain. Intense specific binding extended caudally from the median eminence onto the ventral surface of the anterior pituitary gland (Figs. 5, 6), raising the possibility that at least a portion of the binding observed throughout this region is actually to cells of the pars tuberalis. The rat area postrema was also intensely labeled, but with the exception of median eminence, other circumventricular organs (organum vasculosum of the lamina terminalis, subfornical organ, subcommisural organ, pineal gland, and posterior pituitary gland) did not contain specific I-MEL binding. Specific binding in the rat SCN was less intense than in median eminence and area postrema. Binding in the paraventricular nucleus and an- 
Figure 3. Saturation curve for I-MEL binding to rat median eminence. Scatchard analysis (inset) indicated an equilibrium dissociation constant $\left(K_{d}\right)$ of 43 pM. Data are from 6 animals at each point, expressed relative to standard conditions (100 pM I-MEL; $100 \%$ $=4.75 \pm 0.47 \mathrm{nCi} / \mathrm{mg})$. SEs for each point were less than 10 percentage points. Specific binding (closed circles) is the difference between total binding (open circles) and nonspecific binding (triangles, determined in the presence of $1 \mu \mathrm{M}$ melatonin).

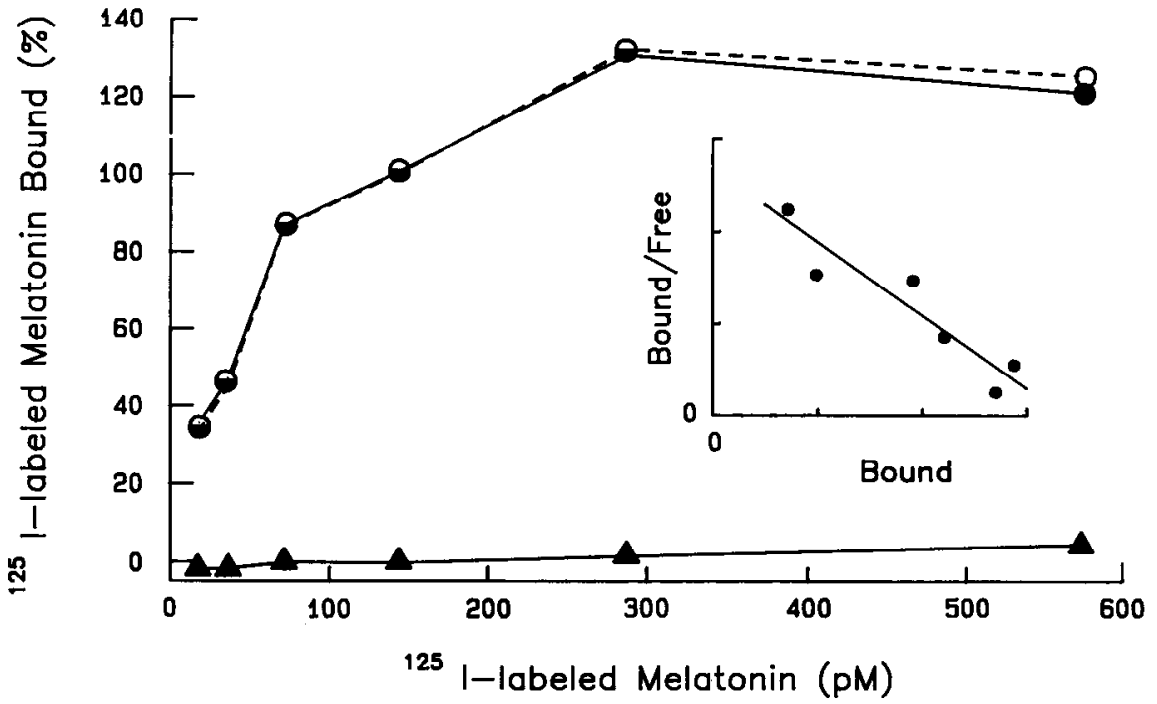

teroventral nucleus of the thalamus and subiculum was less intense than in SCN.

Syrian hamsters. The median eminence was also intensely and consistently labeled by I-MEL in Syrian hamsters (Fig. 7, left-hand column; Table 1). Specific I-MEL binding in the SCN was clearly observed in 8 animals examined recently. In the first 3 animals examined, however, we did not observe specific I-MEL binding in the Syrian hamster SCN (Weaver et al., 1988a, b). The failure to detect SCN labeling in the initial set of sections was probably due to an unidentified technical problem; we are now convinced that the Syrian hamster SCN does contain specific I-MEL binding sites. Specific I-MEL binding was also noted in dorsomedial nucleus of the hypothalamus, paraventricular nucleus of the thalamus, and the medial part of the lateral habenular nucleus (Fig. 7, left-hand column; Table 1).

Djungarian hamsters. Specific labeling was observed only in the hypothalamus (median eminence, SCN) and thalamus (paraventricular and reuniens nuclei, and nucleus of the stria med- ullaris) (Fig. 7, right-hand column; Table 1). Labeling in median eminence was most intense; I-MEL binding sites extended onto the ventral surface of the pituitary. The SCN and paraventricular nucleus of the thalamus were clearly and consistently labeled; binding in reuniens nucleus and the nucleus of the stria medullaris was less intense. The pineal gland did not contain specific I-MEL binding sites.

\section{Distribution of I-MEL binding assessed by radioreceptor assay}

Radioreceptor assay was used to corroborate the site-specific distribution of I-MEL binding sites in rat brain. This independent method confirmed the relatively high amount of I-MEL binding in median eminence, and somewhat lower level of binding in SCN (Fig. 8). Lower levels of binding were observed when the whole hypothalamus was sampled, presumably because of dilution of the binding sites in median eminence and SCN by other hypothalamic tissue containing low levels of binding. In cortex, specific binding was barely detectable.
Figure 4. Pharmacological characterization of I-MEL binding in rat median eminence by quantitative autoradiography. Melatonin $(\mathrm{Mel})$ data are from 2 animals $(100 \%=5.47 \pm 0.62 \mathrm{nCi} /$ $\mathrm{mg}$ ); 2 other animals gave similar results but were not included because their $100 \%$ slide was unusable. Results for other drugs are from 7 animals $(100 \%$ $=4.09 \pm 0.28 \mathrm{nCi} / \mathrm{mg}$ ). 6 - $C l$, 6-chloromelatonin; 5-HT, serotonin; $D A$, dopamine; $N E$, norepinephrine.

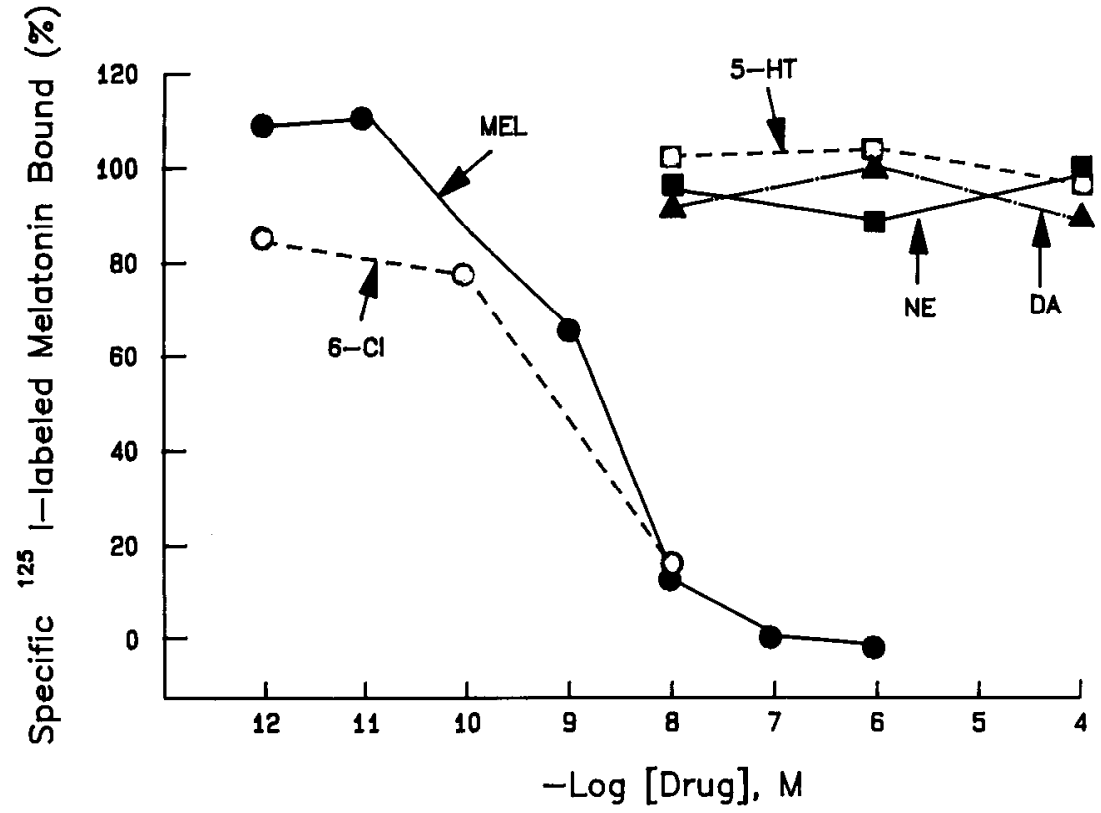



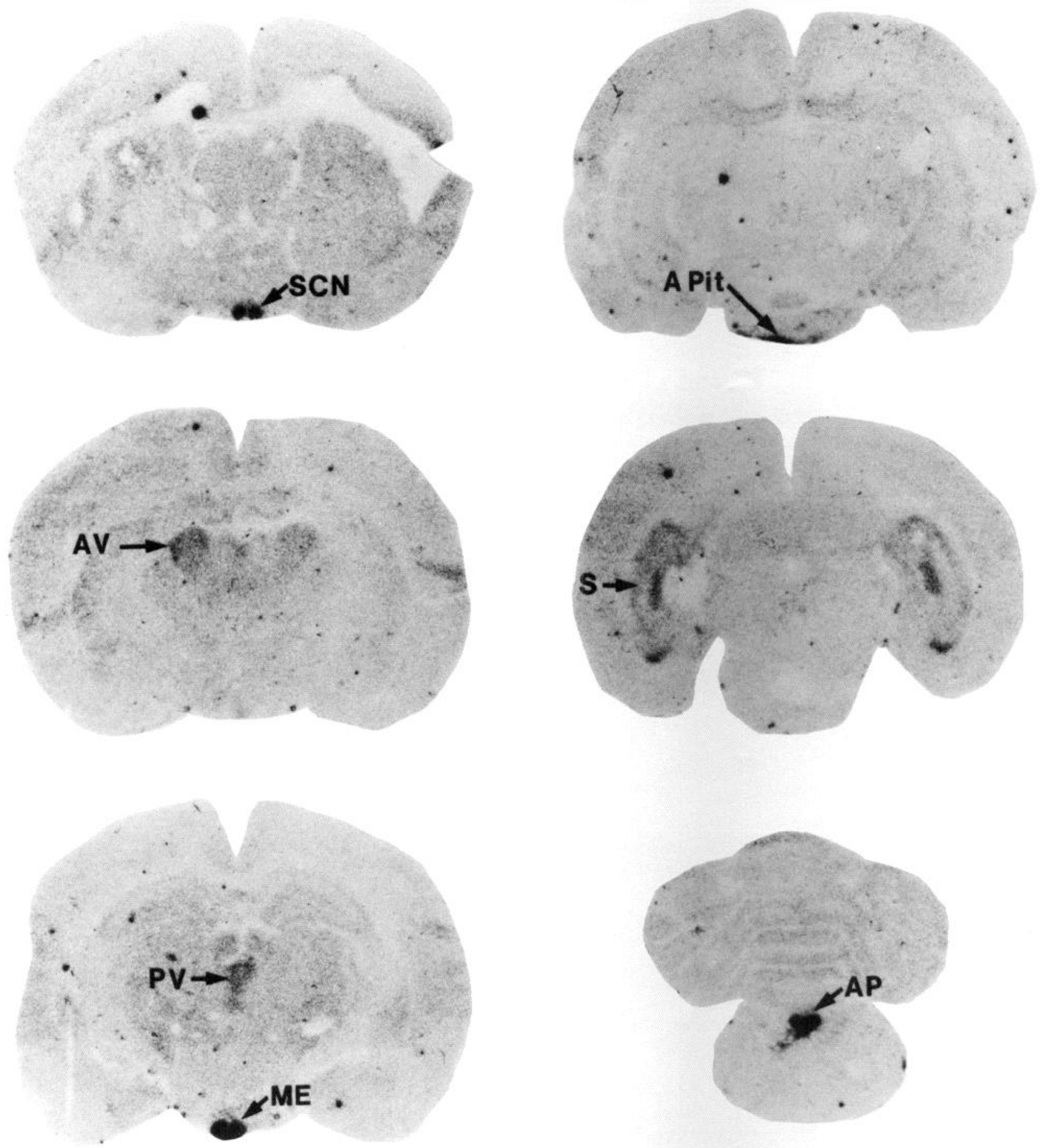

Figure 5. Distribution of I-MEL binding sites in rat brain. Autoradiograms illustrate the areas of specific I-MEL binding. Nonspecific binding was homogeneous and equaled section background. $A P$, area postrema; $A P i t$, anterior pituitary gland; $A V$, anteroventral thalamic nucleus; $M E$, median eminence; $P V$, paraventricular nucleus of the thalamus; $S$, subiculum; $S C N$, suprachiasmatic nucleus.

\section{Discussion}

The I-MEL binding site in rat median eminence exhibits kinetic and pharmacologic characteristics of a melatonin receptor. The I-MEL binding site in rat median eminence is saturable and has high affinity for melatonin, I-MEL, and 6-chloromelatonin. Nonradioactive iodinated melatonin (Dubocovich and Takahashi, 1987; Weaver et al., 1988c) and 6-chloromelatonin (Clemens et al., 1980; Vaughan et al., 1986) are biologically active melato- nin analogs with potency similar to melatonin. Biogenic amınes that do not mimic biological effects of melatonin (serotonin, dopamine, norepinephrine) do not displace I-MEL binding in rat median eminence. The site-specific distribution of I-MEL binding sites, identified autoradiographically and confirmed by radioreceptor assay, further supports that the I-MEL binding site is a specific melatonin receptor, and not a receptor or receptor subtype for another hormone or neurotransmitter. Other recent studies have also used I-MEL to identify high- 

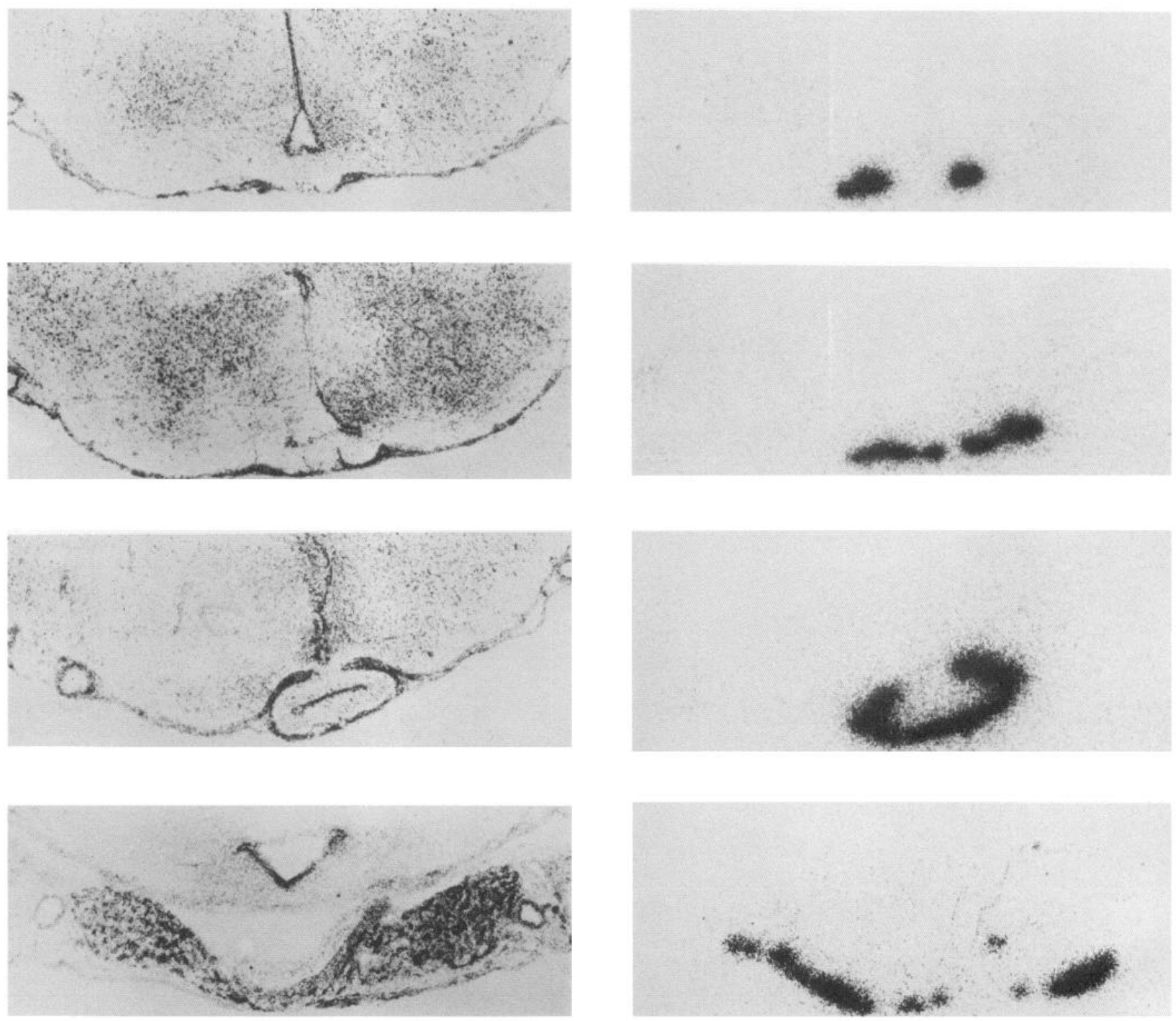

Figure 6. Distribution of I-MEL binding sites in the rat median eminence region. Autoradiograms (right) show the distribution of I-MEL binding; photomicrographs of the same sections after staining with cresyl violet are shown at left. From top to bottom of the figure, sections represent the level of the rostral median eminence, middle median eminence, infundibular stalk, and anterior pituitary gland.

affinity melatonin receptors in vertebrate brain (Dubocovich and Takahashi, 1987; Niles et al., 1987; Vaněček et al., 1987; Duncan et al., 1988; Reppert et al., 1988; Vaněček, 1988a, b; Rivkees et al., 1989). Melatonin concentrations in rodent blood at night are in the picomolar to low nanomolar range (Tamarkin et al.,1985), comparable to the $K_{d}$ values for high-affinity I-MEL binding sites determined in these studies.

While we are confident that we have identified the major sites of I-MEL binding in these 3 rodent species, it is possible that some physiologically relevant sites have been overlooked. Because of the limits of resolution of the film autoradiographic technique, it is unlikely that this method would detect binding to a population of functionally related cells that are not anatomically clustered. For example, cells containing luteinizing hormone-releasing hormone (LHRH) are scattered throughout the preoptic area, anterior hypothalamus, diagonal band, and septum (Silverman et al., 1979; Jennes and Stumpf, 1980; Wit- kin et al., 1982; Petterborg and Paull, 1984). Even if all LHRH cells had I-MEL binding sites, film autoradiography would probably not detect the individual cell bodies because of their scattered distribution. In addition, section frequency, time of day of tissue collection, age, sex, and physiological condition of the animals may influence the distribution of binding sites.

The presence of I-MEL binding in SCN and median eminence confirms earlier observations that these are the major sites of I-MEL binding in rodent brain (Vaněček et al., 1987; Vaněček, 1988b; Weaver et al., 1988c). I-MEL binding sites are present in a limited number of other brain nuclei in a species-specific pattern. On the basis of the present data alone, it is impossible to know which of the brain regions containing I-MEL binding sites mediate physiological responses to melatonin. When considered in the light of published data, however, our data suggest that the $\mathrm{SCN}$ and median eminence are particularly likely sites of melatonin action. 

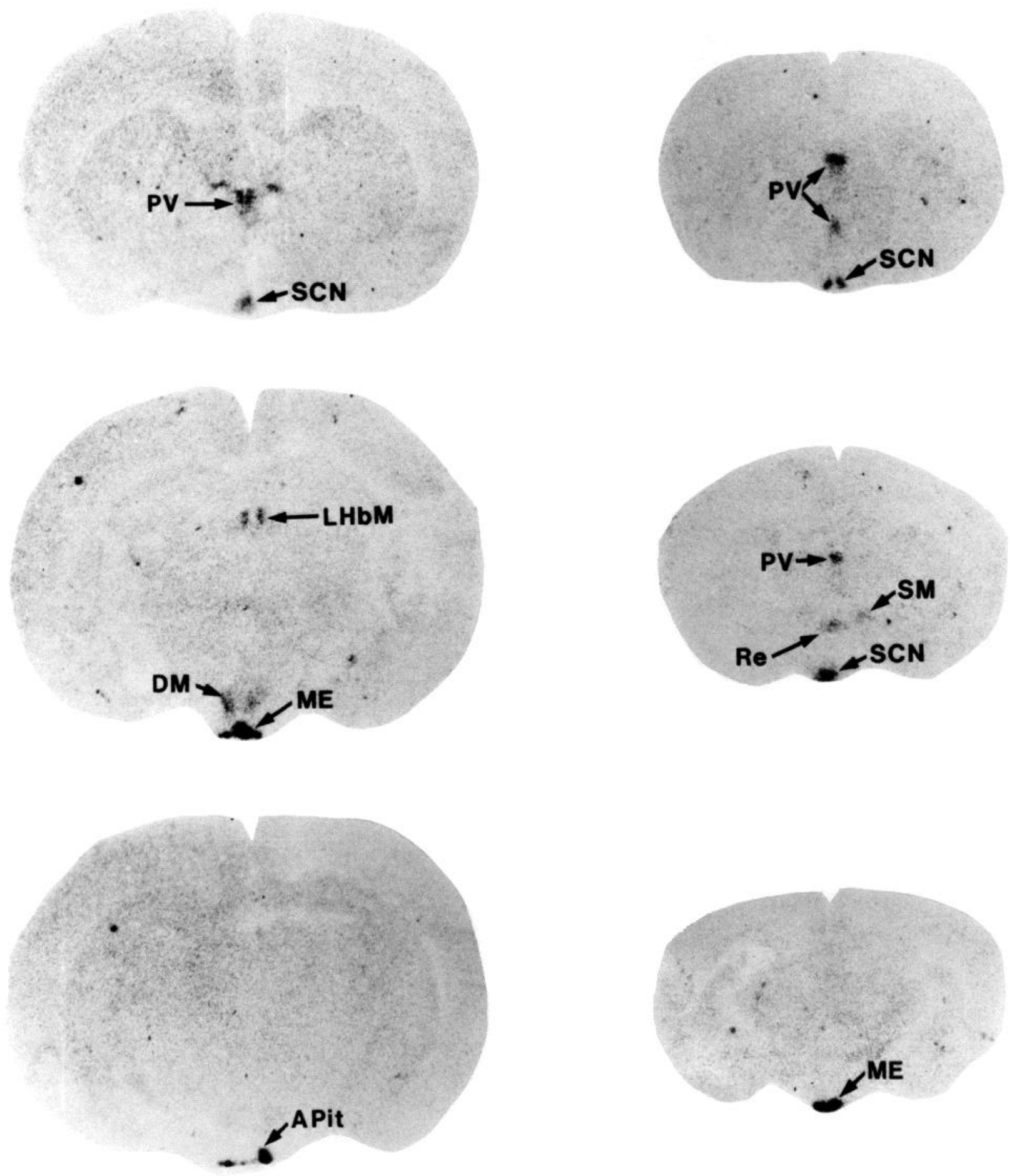

Figure 7. Distribution of I-MEL binding sites in Syrian (left) and Djungarian (right) hamster brain. Autoradiograms illustrate the areas of specific I-MEL binding. Nonspecific binding was homogeneous and equalled section background. APit, anterior pituitary gland; $D M$, dorsomedial nucleus of the hypothalamus; $L H b M$, medial part of the lateral habenular nucleus; $M E$, median eminence; $P V$, paraventricular nucleus of the thalamus; $R e$, reuniens nucleus; $S C N$, suprachiasmatic nucleus; $S M$, nucleus of the stria medullaris.

The SCN are the site of a biological clock in rodents and nonhuman primates (Moore, 1983); the effects of melatonin on circadian rhythmicity in rats (Redman et al., 1983) suggest that melatonin may act in the SCN. Furthermore, the SCN are necessary for the entraining effects of melatonin in rats (Cassone et al., 1986), and melatonin alters the metabolic activity of the SCN (Cassone et al., 1987). Similarly, melatonin effects on cir- cadian rhythmicity in humans (Arendt et al., 1987, 1988) may be mediated by I-MEL binding sites in the human SCN (Reppert et al., 1988). Taken together, these data suggest that melatonin alters circadian rhythmicity by acting on a hypothalamic biological clock, the SCN.

While the SCN may also have a role in photoperiodic responsiveness, previous data on this point are inconclusive. Lo- 


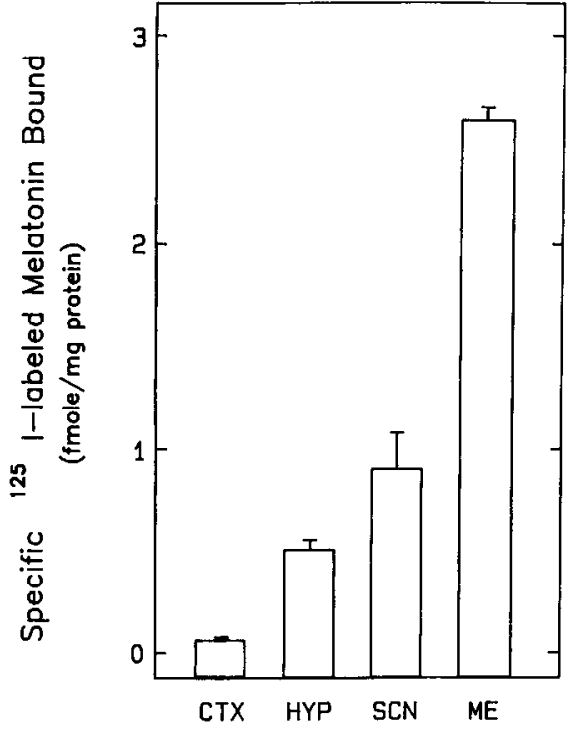

Figure 8. Radioreceptor assay of I-MEL binding sites in the rat. Each point represents the mean \pm SEM of triplicate determinations at a single I-MEL concentration; these values thus represent the relative amount of binding, not the maximum number of binding sites $\left(B_{\max }\right)$. $C T X$, cortex; $H Y P$, hypothalamus; $S C N$, suprachiasmatic nucleus; $M E$, median eminence. Specific binding is the difference between total binding (I-MEL only) and nonspecific binding (I-MEL plus $1 \mu \mathrm{M}$ melatonin).

calization of an antigonadal effect of melatonin to the area near the SCN in mice (Glass and Lynch, 1981) is consistent with the proposal that the SCN may be an important site of melatonin action, but the role of the SCN cannot be directly assessed with this method. Studies to assess the role of the SCN in photoperiodic responses by destroying the nuclei in Syrian hamsters have produced conflicting results (Bittman et al., 1979; Rusak, 1980), perhaps due to methodological differences. Furthermore, the interpretation of lesion studies is complicated by the possibility that lesions may alter responsiveness to melatonin by damaging neural systems regulating hypothalamic-pituitary function without necessarily interrupting melatonin sites of action (see Rusak, 1980, for discussion).

Rats are not overtly photoperiodic, while Djungarian and Syrian hamsters are. Melatonin effects on reproductive physiology have been demonstrated in rats, however. Pubertal development can be delayed in juvenile male rats by timed daily melatonin injections (Sizonenko et al., 1985), and ovulation can be blocked in adult females by acute administration of melatonin on the afternoon of proestrus (Ying and Greep, 1973; Clemens et al., 1980). Furthermore, adult male rats can be made responsive to photoperiod and melatonin treatment (Reiter et al., 1968; Nelson and Zucker, 1981; Wallen et al., 1987). These data suggest that rats possess the substrate for photoperiodic responsiveness (e.g., melatonin receptors), but that expression of photoperiodic responsiveness is normally masked.

The median eminence is critically and intimately involved in hypothalamic-hypophysial function, making it tempting to speculate that this region is a prime site for melatonin effects on reproduction. Melatonin influences the activity of the hypothalamic-pituitary-gonadal axis and times seasonal changes in reproductive function (Karsch et al., 1984; Lincoln et al., 1985; Tamarkin et al., 1985; Underwood and Goldman, 1987); the final link in neural pathways regulating anterior pituitary
Table 1. Distribution of I-MEL binding sites in rodent brain

\begin{tabular}{llll} 
Site & Rat & Syrian & $\begin{array}{c}\text { Djun- } \\
\text { garian }\end{array}$ \\
\hline AP, area postrema & 5 & ND & 0 \\
AV, anteroventral thalamic nucleus & 1 & 0 & 0 \\
DM, dorsomedial hypothalamic nucleus & 0 & 2 & 0 \\
LHbM, lateral nucleus habenula, medial part & 0 & 1 & 0 \\
ME, median eminence & 5 & 5 & 5 \\
PV, paraventricular thalamic nucleus & 1 & 1 & 3 \\
Re, reuniens thalamic nucleus & 0 & 0 & 1 \\
S, subiculum & 1 & 0 & 0 \\
SCN, suprachiasmatic nucleus & 2 & 1 & 3 \\
SM, nucleus of the stria medullaris & 0 & 0 & 1
\end{tabular}

The following system was used to report the intensity of specific I-MEL binding in each site: $0,<0.10 \mathrm{nCi} / \mathrm{mg}$ plastic (Amersham microscale); $1,0.10-0.20 \mathrm{nCi} /$ $\mathrm{mg} ; 2,0.21-0.40 \mathrm{nCi} / \mathrm{mg} ; 3,0.41-0.60 \mathrm{nCi} / \mathrm{mg} ; 4,0.60-1.0 \mathrm{nCi} / \mathrm{mg} ; 5,>1.0 \mathrm{nCi} /$ $\mathrm{mg}$; ND, not determined. Sites not listed were $<0.10 \mathrm{nCi} / \mathrm{mg}$ in all 3 species. Densitometric analysis consisted of examining 2 animals from each species. Sections where the site was most clearly apparent were analyzed; each reading was corrected for nonspecific binding determined on adjacent sections.

function is the population of hypothalamic neurons projecting to the external zone of the median eminence. Recent anatomical studies suggest that, in Syrian hamsters and sheep at least, interaction of LHRH axons within the external zone of the median eminence may be involved in coordinating activity of LHRH cells (Lehman and Silverman, 1988; Lehman et al., 1988). Furthermore, melatonin appears to reduce LHRH release from median eminence, as LHRH content in hypothalamus (Pickard and Silverman, 1979; Jackson et al., 1982; Steger et al., 1982) and median eminence (Petterborg and Paull, 1984; Glass, 1986; Glass and Knotts, 1987) increases with exposure to short days or melatonin treatments. Taken together with our observation of melatonin receptors in the external region of the median eminence, these data suggest that mclatonin receptors in the median eminence play an important role in mediating melatonin effects on reproductive function.

Within the region of the median eminence, I-MEL binding extends from the external zone of the median eminence onto the surface of the infundibular stalk and anterior pituitary gland in a pattern suggesting that at least a portion of the specific I-MEL binding in this region is to cells of the pars tuberalis, a sheath of anterior pituitary-like cells covering the ventral aspect of the median eminence, pituitary stalk, and portions of the pituitary gland (Gross, 1984). Because the pars tuberalis is only 2-4 cells in thickness in these rodent species, our current autoradiographic method cannot distinguish between binding in the external zone of the median eminence and binding in pars tuberalis. Interestingly, the morphology of pars tuberalis in Djungarian hamsters is influenced by photoperiod (Wittkowski et al., 1984, 1988).

Quantitative autoradiography is an increasingly popular method for examining the distribution and properties of receptors/binding sites in the brain (see Kuhar, 1985). In the present study, we have described an in vitro autoradiographic technique for the study of putative melatonin receptors. Considering the extremely limited distribution of I-MEL binding sites in rodent brain, quantitative receptor autoradiography is a powerful method for examining regulation of putative melatonin receptors within individual brain nuclei. 


\section{References}

Arendt, J., M. Aldhous, J. English, V. Marks, and J. H. Arendt (1987) Some effects of jet-lag and their alleviation by melatonin. Ergonomics 30: 1379-1393.

Arendt, J., M. Aldhous, and J. Wright (1988) Synchronization of a disturbed sleep-wake cycle in a blind man by melatonin treatment. Lancet 1: 772-773.

Bittman, E. L., B. D. Goldman, and I. Zucker (1979) Testicular responses to melatonin are altered by lesions of the suprachiasmatic nuclei in golden hamsters. Biol. Reprod. 21: 647-656.

Bradford, M. M. (1976) A rapid and sensitive method for quantitation of microgram quantities of protein utilizing the principle of proteindye binding. Anal. Biochem. 72: 248-254.

Cassone, V. M., M. J. Chesworth, and S. M. Armstrong (1986) Entrainment of rat circadian rhythms by daily injection of melatonin depends upon the hypothalamic suprachiasmatic nuclei. Physiol. Behav. 36: 1111-1121.

Cassone, V. M., M. H. Roberts, and R. Y. Moore (1987) Melatonin inhibits metabolic activity in the rat suprachiasmatic nuclei. Neurosci. Lett. 81: 29-34.

Cheung, P. W., and C. E. McCormack (1982) Failure of pinealectomy or melatonin to alter circadian activity rhythm of the rat. Am. J. Physiol. 242: R261-R264.

Clemens, J. A., M. E. Flaugh, J. Parli, and B. D. Sawyer (1980) Inhibition of luteinizing hormone release and ovulation by 6 -chloroand 6-fluoromelatonin. Neuroendocrinology 30:83-87.

Dubocovich, M. L., and J. S. Takahashi (1987) Use of 2-[125I]iodomelatonin to characterize melatonin binding sites in chicken retina. Proc. Natl. Acad. Sci. USA 84: 3916-3920.

Duncan. M. J., J. S. Takahashi, and M. L. Dubocovich (1988) 2-['25I]Iodomelatonin binding sites in hamster brain membranes: Pharmacological characteristics and regional distribution. Endocrinology 122: 1825-1833.

Glass, J. D. (1986) Short photoperiod-induced gonadal regression: Effects on the gonadotropin-releasing hormone (GnRH) neuronal system of the white-footed mouse, Peromyscus leucopus. Biol. Reprod. 35: 733-743.

Glass, J. D., and L. K. Knotts (1987) A brain site for the antigonadal action of melatonin in the white-footed mouse (Peromyscus leucopus): Involvement of the immunoreactive GnRH neuronal system. Neuroendocrinology 46: 48-55.

Glass, J. D., and G. R. Lynch (1981) Melatonin: Identification of site of antigonadal action in mouse brain. Scicnce 214:821-823.

Gross, D. S. (1984) The mammalian hypophysial pars tuberalis: A comparative immunocytochemical study. Gen. Comp. Endocrinol. 56: 283-298.

Jackson, F. L., J. J. Heindel, J. P. Preslock, and A. S. Berkowitz (1982) Alterations in hypothalamic content of luteinizing hormone-releasing hormone associated with pineal mediated testicular regression in the golden hamster. Biol. Reprod. 31: 436-445.

Jennes, L., and W. E. Stumpf (1980) LHRH-systems in the brain of the golden hamster. Cell Tissue Res. 209: 239-256.

Karsch, F. J., E. L. Bittman, D. L. Foster, R. L. Goodman, S. L. Legan, and J. E. Robinson (1984) Neuroendocrine basis of seasonal reproduction. Rec. Prog. Horm. Res. 40: 185-232.

Kuhar, M. J. (1985) Receptor localization with the microscope. In Neurotransmitter Receptor Binding, 2nd ed., H. I. Yamamura, S. J. Enna, and M. J. Kuhar, eds., pp. 153-176, Raven, New York.

Lehman, M. N., and A. J. Silverman (1988) Ultrastructure of luteinizing hormone-releasing hormone (LHRH) neurons and their projections in the golden hamster. Brain Res. Bull. 20: 211-221.

Lehman, M. N., F. J. Karsch, J. E. Robinson, and A. J. Silverman (1988) Ultrastructure and synaptic organization of luteinizing hormone-releasing hormone (LHRH) neurons in the anestrous ewe. J. Comp. Neurol. 273: 447-458.

Lincoln, D. W., H. M. Fraser, G. A. Lincoln, G. B. Martin, and A. S. McNeilly (1985) Hypothalamic pulse generators. Rec. Prog. Horm. Res. 41: 369-411.

McEachron, P. L., O. J. Tretiak, and O. Feingold (1987) Autoradiography and video densitometry: Image processing with DUMAS. Functional Photography 22: 26-36.

McPherson, G. A. (1985) Analysis of radioligand binding experiments: A collection of computer programs for the IBM PC. J. Pharmacol. Methods 14: 213-228.
Moore, R. Y. (1983) Organization and function of a central nervous system circadian oscillator: The suprachiasmatic hypothalamic nucleus. Fed. Proc. 42: 2783-2789.

Nelson, R. J., and I. Zucker (1981) Photoperiodic control of reproduction in olfactory-bulbectomized rats. Neuroendocrinology 32: 266271

Niles, L. P., D. S. Pickering, and B. G. Sayer (1987) HPLC-purified 2 -[125I]iodomelatonin labels multiple binding sites in hamster brain. Biochem. Biophys. Res. Commun. 147: 949-956.

Paxinos, G., and C. Watson (1985) The Rat Brain in Stereotaxic Coordinates, 2nd ed., Academic, New York.

Petterborg, L. J., and W. K. Paull (1984) An immunocytochemical study of the luteinizing hormone-releasing hormone system in the white-footed mouse: Effect of blinding and melatonin. J. Pineal Res. 1: 371-380.

Pickard, G. E., and A. J. Silverman (1979) Effects of photoperiod on hypothalamic luteinizing hormone releasing hormone in the male hamster. J. Endocrinol. 83: 421-428.

Redman, J., S. Armstrong, and K. T. Ng (1983) Free-running activity rhythms in the rat: Entrainment by melatonin. Science 219: 10891091.

Reiter, R. J., J. C. Hoffmann, and P. H. Rubin (1968) Pineal gland: Influence on gonads of male rats treated with androgen three days after birth. Science 160: 420-421.

Reppert, S. M., D. R. Weaver, S. A. Rivkees, and E. G. Stopa (1988) Putative melatonin receptors in a human biological clock. Science 242: 78-81.

Rivkees, S. A., V. M. Cassone, D. R. Weaver, and S. M. Reppert (1989) Melatonin receptors in chick brain: Characterization and localization. Endocrinology 125: 363-368.

Rusak, B., (1980) Suprachiasmatic lesions prevent an antigonadal effect of melatonin. Biol. Reprod. 22: 148-154.

Shankar, G., and M. L. Dubocovich (1987) 2-[125I]-iodomelatonin labels the same type of melatonin binding site in the chicken brain and retina. FASEB J. 2: A620.

Silverman, A. J., L. C. Krey, and E. A. Zimmerman (1979) A comparative study of the luteinizing hormone releasing hormone (LHRH) neuronal network in mammals. Biol. Reprod. 20:98-110.

Sizonenko, P. C., U. Lang, R. W. Rivest, and M. L. Aubert (1985) The pineal and pubertal development. In Ciba Foundation Symposium, 117: Photoperiodism, Melatonin and the Pineal. D. Clark and S. Evered, eds., pp. 208-230, Pitman, London.

Steger, R. W., A. Bartke, and B. D. Goldman (1982) Alteration in neuroendocrine function during photoperiod-induced testicular atrophy and recrudescence in the golden hamster. Biol. Reprod. 26: 437444.

Tamarkin, L., C. J. Baird, and O. F. X. Almeida (1985) Melatonin: A coordinating signal for mammalian reproduction? Science 227: 714-720.

l'urek, F. W., J. Swann, and D. J. Earnest (1984) Role of the circadian system in reproductive phenomena. Rec. Prog. Horm. Res. 40: 143177.

Underwood, H., and B. D. Goldman (1987) Vertebrate circadian and photoperiodic systems: Role of the pineal gland and melatonin. $\mathbf{J}$. Biol. Rhythms 2: 279-315

Vakkuri, O., E. Lamsa, E. Rahkamaa, H. Ruotsalainen, and J. Leppaluoto (1984) Iodinated melatonin: Preparation and characterization of the molecular structure by mass and 'H NMR spectroscopy. Anal. Biochem. 142: 284-289.

Vaněček, J. (1988a) The melatonin receptors in rat ontogenesis. Neuroendocrinology 48: 201-203.

Vaněček, J. (1988b) Melatonin binding sites. J. Neurochem. 51: 14361440.

Vanécek, J., A. Pavlik, and H. Illnerovâ (1987) Hypothalamic melatonin receptor sites revealed by autoradiography. Brain Res. 435:359362.

Vaughan, M. K., B. A. Richardson, L. J. Petterborg, G. M. Vaughan, and R. J. Reiter (1986) Reproductive effects of 6-chloromelatonin implants and/or injections in male and female Syrian hamsters ( $\mathrm{Me}$ socricetus auratus). J. Reprod. Fertil. 78: 381-387.

Wallen, E. P., M. A. DeRosch, A. Thebert, S. Losee-Olsen, and F. W. Turek (1987) Photoperiodic response in the male laboratory rat. Biol. Reprod. 37: 22-27.

Weaver, D. R., S. A. Rivkees, and S. M. Reppert (1988a) Autoradiographic localization of iodomelatonin binding sites in hypothalamus 
of three rodent species. Abstracts of the 70th Annual Meeting of the Endocrine Society, New Orleans, LA (abstr. 977, p. 265).

Weaver, D. R., S. A. Rivkees, S. M. Reppert, and E. G. Stopa (1988b) Autoradiographic characterization of $2{ }^{-125} \mathrm{I}$-melatonin binding sites in rodent and human brain. Soc. Neurusci. Abstr. 14: 387 (abstr. 156.15).

Weaver, D. R., M. A. A. Namboodiri, and S. M. Reppert (1988c) Iodinated melatonin mimics melatonin action and reveals discrete binding sites in fetal brain. FEBS Lett. 228: 123-127.

Witkin, J. W., C. M. Paden, and A. J. Silverman (1982) The luteinizing hormone-releasing hormone (LHRH) systems in the rat brain. Neuroendocrinology $35: 429-438$.
Wittkowski, W., M. Hewing, K. Hoffmann, M. Bergmann, and J. Fechner (1984) Influence of photoperiod on the ultrastructure of the hypophysial pars tuberalis of the Djungarian hamster, Phodopus sungorus. Cell Tissue Res. 238: 213-216.

Wittkowski, W., M. Bergmann, K. Hoffmann, and F. Pera (1988) Photoperiod-dependent changes in TSH-like immunoreactivity of cells in the hypophysial pars tuberalis of the Djungarian hamster, Phodopus sungorus. Cell Tissue Res. 251: 183-187.

Ying, S.-Y., and R. O. Greep (1973) Inhibition of ovulation by melatonin in the cyclic rat. Endocrinology 92: 333-335. 